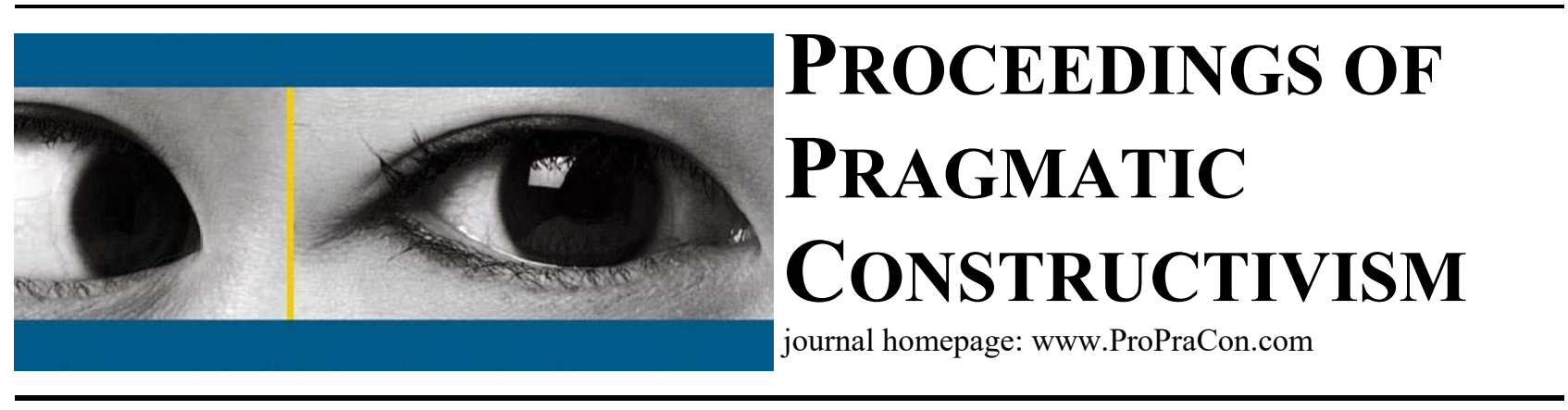

\title{
Helping as the topoi for interventionist research from a pragmatic constructivist point of view
}

\author{
Morten Jakobsen, \\ Department of Management, Aarhus University \\ Email:mja@mgmt.au.dk
}

\begin{abstract}
This research note addresses the question: what criteria must we apply for a topoi that will support interventionist research from a pragmatic constructivist point of view. Interventionist research is about researchers and practitioners who together solve problems by changing practice while developing theory. The researcher is striving for developing and solving a theoretical problem, while the practitioner has a practical problem that needs to be conceptualised and solved. Thereby interventionist research is about constructing a reality for practice and a reality for academia. Interventionist research may take many forms ranging from strong to weak interventions. No matter what form, the driver of interventionist research is here found to be helping. So helping is the topoi of interventionist research. Such claim requires a discussion of the concept of helping. This discussion will be guided by the thoughts of Søren Kierkegaard concerning the art of helping. The discussion in this research note will show that not only the researcher must seek to find the practitioner, and understand what the practitioner may not know in order to help him. Also the practitioner must seek an understanding of what the researcher do not know. The research note will argue that helping based on humbleness and mutual respect is the driver of successful interventionist research. The research note concludes that helping each other into the construction of functioning realities may lead to successful interventionist research projects. However, success is dependent upon that both parties are aware that their own success goes via the success of the other.
\end{abstract}

Keywords: Pragmatic constructivism, interventionist research, helping, topoi.

\section{Introduction}

Within the field of management accounting there is a tradition for interventionist research (e.g. Jönsson \& Lukka, 2006; Suomala, Lyly-Yrjänäinen, Laine, \& Mitchell, 2018; Suomala, Lyly-Yrjänäinen, \& Lukka, 2014). Interventionist research is a form of qualitative research where the researcher directly interacts with practice. The interaction and practical involvement must lead to theoretical contributions in order to qualify as research instead of consulting. The working process of interventionist research involves that both researchers and practitioners have the ambition to change a current situation. The researcher and the practitioner have different motives for entering an interventionist research project. The practitioner has more or less defined practical problem that calls for a solution. Hence, the motive that drives the practitioner is to improve the reality in which she or he is taking part of. The researcher will probably share the interest in solving the practical problem, but in addition to this, the researcher also have to develop and solve a theoretical problem that merits a theoretical contribution to the research field that she or he is part of. This divide in problem focus may cause conflicts in the cooperation if not properly handled. And as will be argued below, such conflict may stand in the way of solving the problem of both the researcher and the practitioner.

For both the practitioner and the researcher, the empirical field of interest is the organisation of the practitioner. Interventionist research is based on a deep understanding of this organisation and the practices that takes place within and along this organisation. As such, interventionist research requires an emic viewpoint (Suomala et al., 2014). 
Interventionist research does not involve experimental methods, where the researcher exposes some kind of treatment to a respondent and the researcher observes the outcome, an approach that would involve an etic perspective (Suomala et al., 2014). The reason for this distinction is that experiments do not see the practitioner as an actor. Experiments presumes that the test person is a re-actor that will respond in a certain way to certain stimuli. Instead, interventionist research implies an active engagement with reasoning according to local rationale and practice. Interventionist research recognises the practitioner as an actor that is capable of contributing to the common ends of the interventionist research project. Recognising the practitioner as a capable actor does not exempt the researcher from any ethical obligations that ought to be associated with traditional social experiments. An interventionist researcher must be fully aware of the authoritative role that she or he is playing in the common problem solving process of interventionist research.

The working process of interventionist research has similarities to a central concept of pragmatic constructivism co-authorship (Nørreklit, 2017). Co-authorship involves professional knowledge and insight of the local practice that situates the reality construction. Co-authorship happens when two or more actors all contribute to the construction of a common reality. Interventionist research is only successful when both parties benefit. This will only happen as long as both parties contribute to the process of solving all relevant problems identified. This means that both parties must contribute to the reality construction of each other's reality. Taking part of an interventionist research process implies that you interacts and take responsibility not only for solving your own problem, but also the other's problem. This means that all parties have to be given room for participation, and all different positions has to be acknowledged and discussed respectfully. Basically this is about how actors work together, and how they start putting words on the problems they face and share ideas of how to solve these problems. Within pragmatic constructivism this process is labelled topoi, and is defined as ways of conceptualizing the actor-world-relations (e.g. Nørreklit, 2017).

The objective of this research note is to discuss criteria for a topoi that will support interventionist research from a pragmatic constructivist point of view.

Interventionist research involves two parties, the researcher and the practitioner. These parties are equal but they also have different objectives of the cooperation. The practitioner have a practical problem to be solved, the researcher is searching for a research problem that can contribute to a relevant theoretical field. These two kinds of problem are often not the same (e.g. Booth, Colomb, \& Williams, 2003). However, the problems can co-exist, and the problems are cosolvable, this is the whole idea behind interventionist research and what must drive the cooperation. Given these different objectives of entering an interventionist research project it is found necessary that the two parties adjust their expectations to each other so that both parties can help each other in solving their problems. In that sense, helping becomes the driver of interventionist research.

In order to guide the following discussion, two research questions will be raised:

1 What does it mean to help?

2 How can helping foster co-authoring of realities in interventionist research.

The ambition of the research note is not to create a new methodology for conducting interventionist research. Instead, the ambition is to point at guidelines for both researchers and practitioners when they join forces and move into the coauthoring of interventionist research.

The research note proceeds as follows. The following section will discuss the concept of helping. The discussion will be guided by the thoughts of Søren Kierkegaard concerning the art of helping. In his authorship, helping is about finding the other where he is, and begin from thereon. The discussion in this research note will show that not only the researcher must seek to find the practitioner, and understand what the practitioner may not know, also the practitioner must seek an understanding of what the researcher do not know. The research note will argue that helping based on humbleness and mutual respect can be the driver of successful interventionist research. The research note concludes that making helping the topoi and driver of interventionist research may lead to interventionist research projects that at the same time allows the researcher to pursue her or his ambition of constructing publishable theoretical knowledge and enables the practitioner to develop and solve her or his practical problem.

\section{The art of helping}

The common understanding of help or helping another person can be illustrated by a man who is waiting at a bus stop together with a young woman with a baby carriage. When the bus arrives, the man asks the young woman if he can help her carry the baby carriage into the bus. What characterises such an event is that both parties can see the problem, and they also know how to solve the problem. Al it takes is a kind request from the man asking: "Can I help you carry the baby carriage into the bus". The young woman would probably answer: "yes please". Then they will grab the baby carriage and lift it into the bus. When the baby carriage is safely inside the bus, the young woman will probably thank the man, and he will gently reply with a "You are welcome". What characterises such a situation is that both parties are able to identify the same problem, and they also know how to solve the problem. From a pragmatic constructivist point of 
view you can say that they share perceptions of reality and are thereby able to co-author the solution of this simple problem.

Helping in relation to interventionist research is different compared to the everyday situation explained above. First, in the example above both the young woman and the man face the same problem - a baby carriage including a baby needs to get safely on board the bus. It will have different consequences for the two people if the problem is not solved, but motives for both the man and the woman can be found for not leaving the baby carriage at the bus stop. When we look at an interventionist research project the researcher and the practitioner are not facing the same problems. The researcher are looking for and have to solve research problems, because this is her or his motive for entering the research project. The practitioner face a practical problem that needs to be fixed in order to make her or his reality work. Hence what is needed is that the two parties must construct common means in order to reach each their ends. Second, carrying a baby carriage into a bus is a well-known problem that we have a known solution for. You can say that the facts and the possibility around such a problem are well defined; what it takes is two people that share values, and communication to begin the action. Interventionist research problems are per definition not fully defined, this is part of a project, and for sure, there is not an obvious solution, because then there would not be a research project in the first place. The situation of the researcher and the practitioner is that they have to work together and the success of each of them is dependent on the success of the other. Such a situation can only be solved if they find a form of helping each other that mobilises the advantages each of them may possess and reduces the weaknesses they may carry.

The literature discussing the concept help is scarce. Instead, the search leads to a similar concept, reciprocal altruism, defined as the exchange of goods and services between individuals (e.g. Ashton, Paunonen, Helmes, \& Jackson, 1998; Boyd, 1988; Brosnan \& De Waal, 2002). These texts often discuss motives for reciprocal altruism, but when it comes to principles of how to help the help from existing literature is not that obvious. However, help from the Danish philosopher Søren Kierkegaard can be used. In his book "The Point of view for my work as an author" he writes: "If One Is Truly to Succeed in Leading a person to a Specific Place, One must First and Foremost Take Care to Find Him Where He Is and Begin There. This is the secret in the entire art of helping. Anyone who cannot do this is himself under a delusion if he thinks he is able to help someone else. In order truly to help someone else, I must understand more than he - but certainly first and foremost understand what he understands. If I do not do that, then my greater understanding does not help him at all. If I nevertheless want to assert my greater understanding, then it is because I am vain or proud, then basically instead of benefiting him I really want to be admired by him. But all true helping begins with a humbling. The helper must first humble himself under the person he wants to help and thereby understand that to help is not to dominate but to serve, that to help is not to be the most dominating but the most patient, that to help is a willingness for the time being to put up with being in the wrong and not understanding what the other understands. "(Qoute from Hong \& Hong, 1998) ${ }^{1}$. Most of Kierkegaard's writings were written in a sarcastic and ironic tone. This means that his texts has to be read and understood with caution. Often the real message is the opposite of what the text says. However the quote is taken from one of the last books that Kierkegaard wrote and is published as a kind of postscript where he accounts for his authorship. As such we dare take the words at face value.

Before we continue a few words about the applicability of the philosophy of Søren Kierkegaard regarding pragmatic constructivism might be appropriate. Kierkegaard explicitly subscribes to Cristian values, and his authorship revolves around developing a Cristian existence as human being (Kierkegaard, 1859). He is interested in humans, and he is interested in how to make people reflect upon their existence. Pragmatic constructivism does not subscribe to Christianity or any other religion for that matter. However, pragmatic constructivism includes values, values that might have roots in Christianity but not necessarily. Hence, some kind of recognition of values as guidance for people's action seem to be shared between Kierkegaard and pragmatic constructivism. Kierkegaard say that people develop through reflection. Pragmatic constructivism would say that people seek integration of their reality through searching for (communication) and walking on paths that are factually possible and in consistence with the values of the actor, and that the integration process requires conscious reflection by the actor. Søren Kierkegaard's existentialistic philosophy is not identical to pragmatic constructivism. Nevertheless, the two philosophies have similarities in their approach to how to recognise and meet humans as reflective actors. Thereby it is found reasonable to use Søren Kierkegaard as inspiration for developing the ideas of helping in this research note.

In order to address if the quote from Kierkegaard can provide us with an answer to the question concerning help as a topoi for interventionist research within pragmatic constructivism some passages of the quote needs to be discussed. The first passage in the quote that will be discussed is: “... take care to find him and begin there...”. From the perspective of the researcher such an approach has the implication that in order to help the practitioner solve his or her practical problem, then the researcher must understand the situation of the practitioner. At first sight, one might argue that this is

\footnotetext{
${ }^{1}$ Hong \& Hong, 1998 is an English translation of the original Danish text. The translation can also be found from the website: https://teol.ku.dk/skc/sab/citater/ published by the Søren Kierkegaard Research Centre at Univerity of Copenhagen.
} 
not an issue for a trained researcher. Most research methods based on interpretive or qualitative principles typically has such an inherent approach. One example is Arbnor and Bjerke (2008) and their actor based method. Of cause, the researcher may happen to forget the situation of the practitioner, but since an awareness of this pitfall is made explicit in most research methods, a trained researcher will probably make an effort to understand the situation of the practitioner. However, research methods are written and followed in order to solve research problems in a way that can justify research criteria. Often the methods are also designed to support describing a case, and to analyse the case through a more or less predetermined theoretical lens. Under such circumstances the practitioner and practice becomes objects for research. In itself such an approach is an act of proudness and vain. However, more important such an approach may exclude the researcher from learning from practice and thereby create knowledge instead of doing re-search. Re-search in the sense of reproducing existing knowledge and reconfirming own beliefs about reality. Suomala et al. (2018, p. 16) discuss the importance developing a good relationship and understanding in the initial stages of the relationship. They provide an example of an interventionist researcher who participated in the practical assembly work in order to get a deep understanding of the hands-on practices of the organisation in which the project would take place. In that sense the researcher really made an attempt to become part of the emic domain of the practitioner. As such the examples shows the importance of really wanting to understand the practitioner on the premises of the practitioner when doing interventionist research because this understanding is the foundation for helping.

The second passage that needs further discussion is the passage: "I must understand more than he-but certainly first and foremost understand what he understands." When doing interventionist research, solving research problems goes via solving practical problems. These problems may be trivial for the researcher. The researcher may thereby have a tendency towards suggesting standard solutions to the practitioner's problem. It may be the case that this standard solution can actually solve the practical problem. Nevertheless, this is not the point. The point is, that by proposing standard solutions, the researcher disregards that the practitioner is an actor on equal terms as the researcher. The researcher may ignore to find the practitioner where he is. Thereby the researcher can easily end up being perceived as proud or vein, and thereby unable to help the practitioner. This is of cause a violation of the co-authorship relation that in itself may harm the relationship. But what might be even worse is that the researcher will exclude himself from gaining knowledge that could actually enrich the solution to the research problem. If the researcher is perceived as being arrogant and unapproachable, it is unlikely that the practitioner will invite the researcher into his reality and share it with the researcher. Thereby the whole reason for entering research in an interventionist way has collapsed.

Though having a humble attitude seem to have advantages in relation to building a helpful relationship, humbleness may also have the disadvantage that it sends a signal of insecurity. As mentioned, the practitioner is likely to enter an interventionist research project with the aim of getting a problem solved. In that sense the practitioner may have the initial feeling that she puts her faith in the hands of the researcher because the researcher may be seen as an authoritative person. If the researcher overplays the humble role, the practitioner may start questioning this authority. Consequently, the practitioner may not be willing to engage in the interventionist research project because the practitioner do not feel certain that the researcher actually possess the skills to help the practitioner. This indicates that at the initial stages of a research process the researcher somehow has to balance between signalling authority and thereby securing a solution to the practitioner's problem, and on the other side having a suitable open and humble attitude towards the practitioner and the situation that she or he is facing.

What about the practitioner? He or she may not have an academic training and probably not research experience. Thereby the urge for finding the other may not be inherent in the way that the practitioner approaches the interventionist research project. However, finding the researcher is just as important for a successful interventionist research project as that the researcher wants to find the practitioner. At least if we take the quote from Kierkegaard as guideline for a topoi for interventionist research. Doing so assumes that the practitioner has accepted to help the researcher in solving her or his research problem. This acceptance includes an obligation to find the researcher where she or he is. It also means that the practitioner must put the researcher first and acquire some patience. This may be a challenge, especially if the practitioner has an expectation of a quick fix solution to hers or his practical problem. A harsh reply to such an expectation could be that the practitioner under such circumstances should have bought a consultant. For sure such a remark would be a sign of arrogance. Instead attention should be pointed towards that attempts to find the researcher where she or he is not only helping the researcher to solve his problem. Finding the researcher may also be a chance for the practitioner to qualify the solution to his own practical problem. This qualification contains not only the answer, but also the reasons for why the solution is right. Thereby the practitioner may have improved his possibilities for building pro-active truth around future challenges he may find.

So far this research note has discussed how the two parties in an interventionist research project has different problems to be solved in order to end a successful interventionist research project. The practitioner has a practical problem and the researcher must develop and solve a theoretical problem. In itself this may not be problematic, but the claim raised is that the two problems can only be solved if the parties help each other. Where helping requires a deep and respectful understanding of the other. In the current interventionist research literature, it is well described how the researcher can become part of the emic domain of the practitioner(e.g. Suomala et al., 2018). But what the discussion in this research 
note implies is that the practitioner must also make an effort to work her or his way into the emic domain of the researcher in order to be able to help the researcher solve her or his research problem. In that sense interventionist research becomes a matter of integrating the emic and the etic domains. This means that the initial stages of an interventionist research project has to cope with more than factually based topics like financing, access to the organisation, confidentiality etc. In addition to these, there also has to be some kind of clarification of the potentially different motives for engaging in an interventionist research project.

\section{Discussion and concluding remarks}

The research note has been arguing that interventionist research is a matter of co-authoring, and the topoi that should be the leading idea of practice is helping. The definition of helping has been to seek to find the other where he is, and from thereon support the other into constructing a functioning reality. Co-authoring involves the common creation of not one reality, but two side-lined realities. The practitioner is interested in solving a practical problem, and the researcher is interested in solving a research problem. The premise is that the two parties are committed to help solving each other's problems. The co-authoring process can only be made via the other. In that sense a successful interventionist research project can only be achieved through helping the other. The implication of this analysis is that both parties becomes highly dependent upon each other. This can create a strong motivation for cooperation. But only if both parties are aware of how they are dependent on each other, and that success for the individual can only happen if the other also has the experience of a successful outcome.

This research note has not brought any empirical evidence that can support the argument raised. The research note has had the ambition to share and perhaps open a discussion with those who would like to participate. The research note can hopefully inspire for methodological research that will set focus on the role of the practitioner when interventionist research projects are conducted.

\section{References}

Arbnor, I., \& Bjerke, B. (2008). Methodology for creating business knowledge: Sage Publications Ltd.

Ashton, M. C., Paunonen, S. V., Helmes, E., \& Jackson, D. N. (1998). Kin altruism, reciprocal altruism, and the Big Five personality factors. Evolution and Human Behavior, 19(4), 243-255.

Booth, W. C., Colomb, G. G., \& Williams, J. M. (2003). The craft of research: University of Chicago press.

Boyd, R. (1988). Is the repeated prisoner's dilemma a good model of reciprocal altruism? Ethology and Sociobiology, 9(2), 211-222.

Brosnan, S. F., \& De Waal, F. B. (2002). A proximate perspective on reciprocal altruism. Human Nature, 13(1), 129-152.

Hong, H., \& Hong, E. (1998). The point of view for my work as an author. Princeton University Press, 1998, chapter IA, §2, p. 45 :

Jönsson, S., \& Lukka, K. (2006). There and back again: doing interventionist research in management accounting. Handbooks of management accounting research, 1, 373-397.

Kierkegaard, S. A. (1859). Synspunktet for min Forfatter-Virksomhed. En ligefrem Meddelelse, Rapport til Historien. København: C.A. Reitzels Forlag.

Nørreklit, L. (2017). Actor-reality Construction. In H. Nørreklit (Ed.), A Philosophy of Management Accounting (pp. 23-71): Routledge.

Suomala, P., Lyly-Yrjänäinen, J., Laine, T., \& Mitchell, F. (2018). Interventionist Management Accounting Research. Routledge.

Suomala, P., Lyly-Yrjänäinen, J., \& Lukka, K. (2014). Battlefield around interventions: A reflective analysis of conducting interventionist research in management accounting. Management Accounting Research, 25(4), 304-314. 